\title{
DIÁSPORA, DUELO Y MEMORIA EN MI HERMANO DE JAMAICA KINCAID ${ }^{1}$
}

\author{
Lucía Stecher \\ Universidad Alberto Hurtado \\ 1stecher@uahurtado.cl
}

RESUMEN / ABSTRACT

El presente artículo desarrolla un análisis de la novela autobiográfica Mi hermano de la escritora caribeña residente en Estados Unidos Jamaica Kincaid. Se muestra cómo a nivel de sus contenidos manifiestos -y también de la construcción de sí misma que hace Kincaid en una serie de entrevistas- la narrativa de esta autora se diferencia de la producida por otros autores diaspóricos contemporáneos, sobre todo en su reticencia a comprometerse en proyectos colectivos de asociación transcultural. Sin embargo, una lectura detenida del trabajo de duelo representado por la escritura de Mi hermano muestra cómo el discurso autoconsciente de la narradora-protagonista es subvertido por la fragilidad y vulnerabilidad a que la exponen la enfermedad y muerte de un ser querido.

Palabras clave: Jamaica Kincaid, diáspora literaria, memoria, duelo, comunidad.

This article analyses the autobiographical novel My Brother written by Jamaica Kincaid, a Caribbean writer who lives in the United States of America. The article shows how Kincaid's narrative texts and her self construction as a writer differ from the literature of other diasporic writers, especially regarding her reluctance to participate in collective projects of transcultural association. Nevertheless, a careful reading of the mourning represented in My Brother shows how the narrator's self-conscious discourse is subverted by the fragility and vulnerability caused by the illness and death of a beloved person.

KEY WORDS: Jamaica Kincaid, literary diaspora, memory, bereavement, community.

${ }^{1}$ Este artículo es resultado de la investigación realizada en el marco del proyecto Fondecyt 11080065, dirigido por la autora. 
A partir de los años 80 del siglo XX, se fue consolidando en el campo cultural norteamericano un interés creciente por obras literarias de autores provenientes de América Latina y el Caribe. Nuevos escritores - muchas veces clasificados como "étnicos" por la industria editorial-y también lectores pertenecientes a comunidades de exiliados y migrantes de estas regiones están enriqueciendo y transformando el mundo de la literatura en Estados Unidos. De la mano de esta producción y recepción literarias, han surgido revistas especializadas y un gran número de estudios críticos dedicados a interpretar las propuestas estéticas, políticas e ideológicas de estos textos. El interés crítico por esta producción literaria se ve refrendado por la gran cantidad de entrevistas realizadas a los escritores, tanto en medios académicos como periodísticos. En 2008, la entrega del premio Pulitzer a Junot Díaz por La maravillosa vida breve de Oscar Wao confirma la importancia de esta literatura en el ámbito de las letras en el país del norte ${ }^{2}$.

En este artículo presento un análisis de Mi hermano, novela autobiográfica de una de las autoras que por su origen, experiencia migratoria y éxito literario puede ser considerada como parte del grupo de escritoras y escritores caribeños más reconocidos, estudiados y leídos en Estados Unidos. Se trata de Jamaica Kincaid, que llegó desde la isla caribeña de Antigua a los Estados Unidos a los diecisiete años, enviada por sus padres a trabajar como niña au-pair y cuya carrera de escritora se inició con la publicación de sus primeros cuentos en el New York Times (reunidos posteriormente en el volumen de cuentos At the Bottom of the River). Sus novelas (Annie John, Lucy, Autobiografia de mi madre, Mi hermano, Mr. Potter ${ }^{3}$ ) y libros de ensayos (Un pequeño lugar, My Garden (Book), A Walk Through the Himalayas) han sido ampliamente comentados por la crítica académica y periodística. Si bien Kincaid muchas veces es leída desde posturas teóricas que destacan las coincidencias entre su obra y la de otros autores diaspóricos contemporáneos, en mi opinión son mucho más importantes los elementos que la diferencian de ellos y que en muchas ocasiones la autora parece cultivar y acentuar de forma radical. El mismo "personaje" que Kincaid construye en sus entrevistas, es muy distinto

\footnotetext{
2 Junot Díaz es el segundo "latino" o "hispano" en obtener el Pulitzer. El primero fue el escritor cubano-americano Oscar Hijuelos, quien lo obtuvo en 1990 por Los reyes del mambo tocan canciones de amor.

${ }^{3}$ Los libros que cuentan con traducción al castellano son citados en este idioma. En los últimos años, la Editorial LOM ha publicado dos libros de Jamaica Kincaid: Autobiografía de mi madre y Mi hermano.
} 
al que reconocemos en otros escritores y escritoras de origen latinoamericano y caribeño. Me interesa entonces dar cuenta de esta "diferencia" de Kincaid, que tiene que ver con el carácter ambiguo de su escritura, que permite interpretaciones muy distintas y en ocasiones contradictorias. La lectura que propongo de Mi hermano se basa precisamente en reconocer la coexistencia de discursos en conflicto al interior del texto y la dificultad de reconciliarlos. Por otra parte, me interesa mostrar cómo la representación que hace Kincaid del trabajo de duelo - en torno a la muerte de su hermano, pero también a su desarraigo- constituye un eje que articula su texto autobiográfico y que permite la emergencia de otras facetas de la narradora protagonista y sus relaciones con los "otros significativos" de su vida en Antigua.

\section{LENGUA, MEMORIA Y COMUNIDAD EN LA LITERATURA DIASPÓRICA ${ }^{4}$ CONTEMPORÁNEA}

La vitalidad de la literatura diaspórica contemporánea en Estados Unidos (producida por autoras y autores provenientes tanto de América Latina y el Caribe, como de países asiáticos y, en menor medida, africanos) ha conllevado una serie de esfuerzos críticos por establecer los rasgos comunes, las coincidencias estéticas y los proyectos políticos que se expresan en estas escrituras. En el caso de los escritores latinos y caribeños, se destaca la preocupación por reconstruir los lazos de la comunidad migrante al interior de Estados Unidos y también con el país de origen. La ficción de estos autores revisa e interroga los referentes identitarios transmitidos por sus padres y los contrasta y reconfigura a la luz de la experiencia migratoria en Estados Unidos. Pese a la distancia geográfica y a que no comparten ni el territorio ni la cotidianidad con los connacionales que no emigraron, los miembros de estas comunidades migrantes reclaman su pertenencia a la nación de origen, a la vez que revisan y obligan a reconceptualizar nociones como las de "nación", "pertenencia", "territorio", "lengua materna" y las relaciones entre estos términos.

${ }^{4}$ A lo largo de este texto se alternan los términos "literatura diaspórica" y "literatura migrante" debido a que la producción que estamos analizando puede ser concebida de ambas maneras. Para una clara distinción entre los conceptos semánticamente relacionados de "exilio", "diáspora” y "migración” ver Clifford y Torres Saillant. 
La afirmación de Adorno de que "en el exilio el único hogar es la escritura", es citada por muchos críticos que consideran que los escritores diaspóricos están construyendo y reconstruyendo sus comunidades en el lenguaje y la ficción (Ramos). En sus mundos novelísticos se estarían ensayando nuevos discursos y lenguajes que dan cuenta e interpretan las experiencias migratorias y las dificultades del encuentro/choque entre culturas distintas, también en términos de prestigio simbólico y posibilidades materiales de expresión y representación. Lo que Said denomina la visión en contrapunto del exiliado, configura en una medida importante la perspectiva de estas textualidades, las cuales se vuelcan críticamente tanto sobre sus mundos de origen como sobre el de llegada.

Esta literatura diaspórica vuelve una y otra vez sobre experiencias de migración de los propios autores y su comunidad. Algunos críticos (Lehmann) la han vinculado a las narrativas de esclavos, que destacan la importancia de la alfabetización para conseguir la libertad y que entrelazan las experiencias de sus autores con las de otros esclavos. Se trata de narrativas que conjugan la historia particular con la colectiva, abriendo espacios para una diversidad de voces. Por otra parte, también constituye un rasgo distintivo de las escrituras migrantes contemporáneas, la producción de textos que rescatan la historia de los países o región de origen. Más que de novelas históricas en sentido estricto se trata de esfuerzos por recuperar las miradas, vivencias y rostros de sujetos individuales y colectivos excluidos de la historiografía oficial. Novelas como Cosecha de huesos (1999) de Danticat, La maravillosa vida breve de Oscar Wao (2009) de Junot Díaz, No Telephone to Heaven (1996) de Michelle Cliff, En el tiempo de las mariposas (2007) y En el nombre de Salomé (2003) de Julia Álvarez, entre otras, se caracterizan por dar voz y presencia textual a personajes escasamente representados en los discursos históricos nacionales (o con una representación sesgada en el caso de las heroínas de Julia Álvarez). Esta literatura, además, suele desarrollar explícita o implícitamente una reflexión en torno al idioma de escritura, a la creación de nuevos códigos lingüísticos surgidos de la coexistencia del inglés y el idioma del país de origen. Aunque muchos de estos escritores escriben en inglés, no se trata de una asimilación "neutral" a este idioma, sino más bien de una apropiación y rearticulación de su léxico, sintaxis y ritmo adecuadas a la representación de mundos y experiencias que por lo general son bilingües y están atravesados por un permanente y vapuleado "code-switching" o alternancia de códigos (Torres). 
Si se compara la obra de Kincaid con la de otros autores caribeños contemporáneos que han llegado como migrantes económicos a Estados Unidos, es posible reconocer importantes diferencias tanto en la representación de la migración y la experiencia de vida en el país de acogida, como de los discursos producidos con respecto al lugar de origen. Así, escritores como Junot Díaz y Edwidge Danticat tienen una producción literaria en la que la migración aparece como proceso que va más allá de decisiones personales, que tiene un trasfondo político, económico y social que trasciende la voluntad de individuos particulares. Los personajes que crean estos autores tienen experiencias migratorias que los llevan del margen de sus sociedades de origen a un lugar equivalente en la sociedad norteamericana: barrios marginales de Nueva York, en los que la vida transcurre en castellano, spanglish o creole haitiano, en que la violencia y la exclusión van de la mano de una aparente oferta de oportunidades de progreso solo alcanzable a fuerza de tener varios trabajos, pocas horas de sueño y el riesgo permanente de ser arrestado, deportado o asaltado.

Aunque la ficción de Kincaid también está atravesada por una fuerte presencia de elementos autobiográficos relacionados con su experiencia migratoria, no hay en ella ningún esfuerzo manifiesto de articulación de lazos comunitarios ni de expresión de experiencias colectivas. Su autodefinición en una entrevista como "bestia singular" (Buckner) puede transferirse también a la construcción de sus protagonistas: mujeres solas, furiosamente críticas de su isla natal (siempre Antigua), desconfiadas frente a las relaciones con cualquier otra persona y mucho más si ésta es (o se parece a) su madre y tenaces en el proyecto de desarrollar una carrera artística en el país de emigración (Lucy, Mi hermano). Incluso un tema tan sensible para otros escritores diaspóricos, como es la inclusión y valoración de los idiomas que hablaron en su infancia, es tratado en forma totalmente opuesta por Jamaica Kincaid. En Mi hermano relega a acotaciones entre paréntesis el criollo inglés que habla su familia en Antigua, no ahorrándose comentarios sobre el carácter bajo de esa versión "degradada" de la lengua metropolitana, de la cual se distancia permanentemente:

Llevaba tanto tiempo viviendo lejos de mi hogar que ya no entendía con rapidez el inglés que él hablaba y siempre tenía que hacerle repetir las cosas; yo ya no hablaba el mismo inglés que él, y, cuando le decía algo, se me quedaba mirando y a veces se reía de mi abiertamente. Hablas raro, me decía (9). 
Pero muchos días más tarde, mi madre me dijo, Se ha puesto tan negro, la enfermedad ha ennegrecido tanto su piel (me lo dijo en este inglés, hizo un esfuerzo para hablarme en el inglés que ahora entiendo sin dificultad). Tenía los labios de color escarlata y cubiertos de pequeñas llagas con costras doradas. Cuando abrió los ojos y me vio, soltó el sonido que llamamos truups (se consigue juntando los dientes al tiempo que se sacan los labios hacia fuera y se aspira con fuerza). Dijo que no había creído que yo fuera a verle ("Mí oí decir que venías, pero Nome tragué que fueras a venir de verdá") (10).

Las citas grafican gestos que atraviesan toda la escritura de Mi hermano: en primer lugar, la distancia entre la narradora y las personas de su familia y país de origen, ejemplarmente expresada en las diferencias lingüísticas, que por momentos amenazan el éxito de la comunicación. Por otra parte, las palabras de los otros son siempre confinadas al espacio entre paréntesis, a un aparte controlado que interrumpe pero no amenaza el flujo de los pensamientos de la narradora. La segunda cita ilustra, además, un tercer elemento distintivo de este texto: el hecho de estar construido, narrado, orientado, hacia un lector ideal que es norteamericano. En este sentido es interesante el posicionamiento de la narradora cuando dice "soltó el sonido que llamamos truups". Podría haber escrito "llaman", afirmando su adquirida exterioridad con respecto al mundo de Antigua, pero se incluye en él y aporta al lector anglo una explicación autorizada, de informante nativa, de cómo se produce ese sonido. A lo largo del texto la narradora hace y deshace varias veces el mismo camino, uno que la aleja y distancia para luego devolverla al lugar de la cercanía y hasta la identificación (con su familia, con su país de origen). Esta especie de resorte de los afectos envuelve una narrativa marcada profundamente por la ambivalencia y la ambigüedad.

Fuera ya de la textualidad de Mi hermano, Kincaid despliega también gestos de diferenciación, tanto de su país de origen como de todo aquello que ha sido valorado positivamente en relación con otras escrituras migrantes: ella es una "bestia", no busca comunidad, escribe en inglés standard y asume una actitud despectiva hacia quienes hablan creole. Por supuesto que es perfectamente consciente del rechazo y escozor que suscitan muchas de sus afirmaciones entre lectores de distinto origen, pero parte de su construcción como autora se basa en su carácter provocador ${ }^{5}$.

5 De hecho, la publicación de Un pequeño lugar le valió ser declarada persona non grata en Antigua. El New York Times que la acogiera favorablemente con sus primeras publicaciones, 
Para explicar la virulencia del odio de las protagonistas de las novelas de Kincaid hacia sus madres, muchos críticos han recurrido a interpretaciones de corte sicoanalítico. Vistas desde esta perspectiva, en las novelas de Kincaid se representan los dolores y dificultades asociadas a los procesos de subjetivación, sobre todo de niñas y mujeres (Balutansky; Caton; Covi; Vilches). Lo que a nivel de contenido manifiesto resulta en algunos casos extremo y hasta inverosímil, es iluminador si se lee en relación con las propuestas de Freud, Lacan y el trabajo de críticas feministas como Nancy Chodorow. Estas lecturas en algunos casos se ven complementadas por una segunda vertiente de la crítica en torno a la obra de Kincaid, que se enmarca dentro de la teoría postcolonial. La confluencia de la perspectiva psicoanalítica y postcolonial muestra cómo en las protagonistas y mundos de ficción de Kincaid la individuación se ve afectada por las estructuras coloniales y neocoloniales.

Para la crítica postcolonial que se ha ocupado de ella, la obra de Kincaid forma parte de la corriente de literatura diaspórica contemporánea, caracterizándose por su fuerte denuncia de las situaciones de colonialismo y neocolonialismo en que viven las colonias caribeñas que obtuvieron su independencia en la segunda mitad del siglo XX (entre ellas Antigua). Sin embargo, si bien esas lecturas se sustentan en algunos aspectos del contenido de los textos de Kincaid o en la interpretación de algunas imágenes y metáforas, también es posible cuestionarlas en base a otras dimensiones textuales, a nuestro parecer más representativas de su narrativa. No niego entonces la presencia de una discursividad anticolonial en esta autora, pero sí considero que ésta funciona en forma muy distinta a la de otros escritores diaspóricos. Una de las diferencias fundamentales es la ya mencionada negativa de Kincaid a comprometerse con proyectos colectivos, expresada tanto en las entrevistas concedidas como a través de las narradoras-protagonistas de sus novelas, que ciertamente cumplen el rol de alter-egos de la autora.

criticó severamente este libro, en que la autora denuncia con acritud la condición neocolonial y la explotación por el turismo de su isla de origen. Por mi parte, he constatado las apasionadas reacciones que suscitan los libros de Kincaid al dar como lectura Autobiografía de mi madre y Mi hermano en dos cursos distintos. A los estudiantes de ambos cursos los textos o les gustaron mucho (tanto que escribieron después trabajos y tesis sobre ella) o les provocaron un gran disgusto. Lo que resulta innegable es que la lectura de Kincaid difícilmente es acogida con indiferencia. 
Las lecturas postcoloniales de Mi hermano interpretan el SIDA de Devon y la situación de dependencia en que lo pone con respecto a su hermana -porque solo ella puede comprar y enviar desde Estados Unidos las medicinas que mejoran su calidad de vida y dilatan la muerte- como una alegoría del sometimiento primero colonial de Antigua y posteriormente postcolonial. Hay una escena clave en el texto que sustenta esta interpretación. En una de las visitas a Antigua, Kincaid pasea por las afueras del jardín botánico con su hermano, quien comparte con ella el interés por las plantas:

Mi hermano y yo fuimos paseando hasta el jardín botánico, pero lo encontramos cerrado por reformas. Había estado abandonado, descuidado, durante muchos años, muchos especímenes habían muerto, pero ahora alguien -muy probablemente un canadiense, visto que son tan generosos con la autodestrucción del mundo- un canadiense había dado dinero para que se restaurara el jardín botánico. Paseamos alrededor de todo su perímetro y, con la ayuda de un libro de botánica tropical que yo llevaba, y gracias también a nuestros propios conocimientos, identificamos muchas plantas. Pero entonces nos topamos con un árbol que no éramos capaces de identificar, ni por nosotros mismos ni tampoco recurriendo al libro. Era un árbol, sólo un árbol y, o bien estaba empezando a despertar de un completo letargo, o bien estaba medio muerto y medio vivo. Mi hermano y yo nos obsesionamos con aquel árbol, su corteza, sus hojas, su forma; nos preguntábamos de dónde procedería realmente, qué clase de árbol era. Si en algún momento se le pasó por la cabeza que aquel árbol, saliendo de su letargo, de un profundo sueño de la naturaleza, una muerte temporal, o simplemente medio muerto, guardaba algún parecido con él en aquel preciso momento y lugar, no dijo nada, no me lo dio a entender en absoluto (68-69).

Ramón Soto-Crespo considera que esta escena es clave para la interpretación de la novela, relevando la correspondencia que existe entre el jardín botánico de origen colonial, su posterior deterioro y su dependencia de una inyección de capital extranjero para recuperarse, y la enfermedad de Devon. Como el jardín, este personaje depende de la capacidad adquisitiva de la hermana que migró a Estados Unidos para acceder al AZT. La asimetría entre Kincaid y Devon, la actitud de superioridad que ella exhibe ante su familia de origen, deben ser leídas, según Soto-Crespo, como una representación alegórica de la relación entre Estados Unidos y Antigua. Para este crítico, el duelo que representa 
Kincaid en su texto autobiográfico forma parte de un "estilo político de asociación transcultural" (342) característico de autores diaspóricos.

Si bien esta correspondencia entre la situación del jardín botánico y Devon parece plausible, también es cierto que lo que explicita la narradora es la similitud entre el árbol que no puede clasificar y la situación de su hermano. El árbol lo encuentran en la caminata por las afueras del jardín y ambos hermanos lo inspeccionan sin lograr clasificarlo. Y esto es precisamente lo que hace Kincaid con Devon a lo largo del texto: se pregunta por su verdadera naturaleza, por lo que hay detrás de su apariencia fanfarrona. Y asume, además, que tampoco Devon se conoce verdaderamente, que vive en forma alienada e irresponsable, sin capacidad para desarrollar los talentos que ella sospecha en su interior. El árbol representa a Devon en su dimensión de enigma para la autora y, según ella piensa, también para sí mismo.

Al igual que en sus otras novelas, Kincaid construye en este relato autobiográfico una protagonista que lucha denodadamente por distanciarse de las personas y el entorno con las que vivió su infancia. La energía que demanda esta empresa es tan grande, que el riesgo al fracaso, al colapso de la distancia, acecha en cada recuerdo, en cualquier descuido concebido por la narradora como debilidad. La distancia se sostiene precariamente en la construcción de un universo dicotómico, de polaridades aparentemente irreconciliables. Por un lado la familia elegida, amada sin ambigüedades, sana y próspera, en el ambiente pastoral y protegido de Vermont. Por el otro, la familia de la infancia, impuesta, amenazante, enferma, que forma parte de un mundo culturalmente atrasado, supersticioso y pobre, es decir, de Antigua. A medio camino entre estos extremos se ubica Kincaid, luchando permanentemente por quedar en el lado "correcto", por no ser infectada por la corrupción de su familia de origen. Según su relato, se salvó y fue exitosa por haber emigrado de Antigua, por haber sido capaz de desplegar su talento literario en Estados Unidos. Ese es uno de los contenidos manifiestos de su novela autobiográfica, que si no fuera por otros discursos que la atraviesan podría ser considerada como otro texto celebratorio del American Dream. Al comienzo de Mi hermano, un párrafo suelto, escasamente relacionado con los que lo anteceden y continúan, sugiere la perspectiva deconstructiva que la narradora también desarrolla con relación a sí misma y sus esfuerzos de configuración identitaria:

Nunca hasta ahora había entendido la razón por la que la gente miente acerca de su pasado, por qué dicen ser algo distinto de lo que 
realmente son, por qué inventan una personalidad que no guarda el menor parecido con quienes son en realidad, por qué todo el mundo desea sentirse como si él o ella no formaran parte de nada, no procedieran de nadie, como si simplemente hubieran caído del cielo, como si fueran una totalidad en sí mismos (12-13).

Pero no solo la narradora y sus esfuerzos de auto-construcción prescindente son reconocibles en este párrafo, que ciertamente ilumina el resto del texto en forma oblicua, tiñendo de ambigüedad su discursividad explícita. También es posible atisbar acá una referencia a Devon, que le miente al resto sobre sí mismo, que despliega una actitud egoísta e individualista para protegerse de los demás. Para comprender esto es importante hacer mención a un dato clave de la construcción de esta novela autobiográfica: el hecho de que se presenta como un camino del desconocimiento al conocimiento, del no saber y no entender a una suerte de revelación iluminadora. Hacia el final del libro, la narradora cuenta su encuentro en Chicago, durante la presentación de uno de sus libros, con una mujer que conoció a su hermano en Antigua. Se entera a través de esta mujer de que su hermano era homosexual, que utilizaba su casa como refugio para juntarse con sus amantes, para así quedar al resguardo de la terrible homofobia de la sociedad de Antigua. Sin embargo, aunque en este sentido el texto tiene un desarrollo que podría parecer más lineal -ya lo decía, del desconocimiento al conocimiento- también es posible reconocer la incerteza que socava la estabilidad del trazado recto: cuando escribe sobre la enfermedad y posterior muerte de su hermano, la autoranarradora-protagonista, ya sabe de su homosexualidad. Y, es más, se podría aventurar que es precisamente este secreto tan bien guardado por su hermano el que lo redime ante los ojos de Kincaid, el que la lleva a emprender la escritura de la novela que lo ubica como protagonista a nivel del título. La homosexualidad de Devon lo sitúa en una posición de víctima, ya que en la sociedad de Antigua no la puede vivir libremente. Y no solo eso, sino que frente al conservadurismo de su país, Devon opta por una exhibición ostentosa de su virilidad y galantería heterosexual. Esto que un primer momento resulta intolerable para Kincaid -sobre todo cuando se entera de que después de la mejoría que le permiten las drogas que ella le ha conseguido se acuesta con diversas mujeres sin advertirles de su enfermedad-, después es comprendido en su carácter de bravata que busca distraer la atención de su sociedad.

El descubrimiento de la homosexualidad de Devon le permite a Kincaid iniciar el trabajo de duelo, que se configura en la escritura del libro $M i$ hermano. Es significativo que el encuentro entre Kincaid y la mujer que le 
revela el secreto de Devon ocurra durante el lanzamiento de uno de sus libros, lo que precisamente refuerza la conexión entre este suceso y la actividad literaria de la autora. La muerte de Devon es el centro de un sentimiento de pérdida que impacta en la autora y moviliza, llevando hacia la superficie, los vacíos provocados por sus experiencias previas de desarraigo y distancia.

\section{EL DUELO DE LA DISTANCIA}

Lucy, narradora protagonista de la novela epónima de Jamaica Kincaid, concibe la historia de su vida como duelo inacabable por el más grande amor que tuvo y perdió: el que sintió en su infancia por su madre ("[ [...] durante la mitad de mi vida, diez de mis veinte años, había estado en duelo por el fin de una relación amorosa, quizás el único amor verdadero que conocería en toda mi vida" - piensa Lucy en relación con su madre. Lucy, 132). En sus dos primeras novelas, Kincaid construye mundos de ficción basados en sus propias experiencias, primero como niña en Antigua, más adelante como chica aupair en Nueva York. En ambas historias, la relación más intensa, conflictiva y dolorosa es la que mantiene la protagonista con su madre. Annie John representa el tránsito del amor materno filial más íntimo al distanciamiento y finalmente el odio más profundos entre hija y madre. En la segunda novela, pese a que la protagonista (que aunque cambia de nombre comparte la misma historia infantil de Annie John) se encuentra separada de su madre por vivir en Nueva York, vuelve a describirse el poder omnipresente de la madre y la vulnerabilidad de la hija frente a este ser que ama y odia a la vez.

Con Mi Hermano, nos encontramos por primera vez ante un texto de Kincaid que asume formalmente las características del género autobiográfico. A nivel pragmático, se activa el pacto "del nombre propio" que garantiza al lector que el autor, el narrador y el personaje principal son efectivamente la misma persona, es decir, que comparten un "principio de identidad" (Lejeune) ${ }^{6}$. Pasajes importantes de Annie John y Lucy vuelven a aparecer en este texto, confirmando el carácter autobiográfico que la misma Kincaid

${ }^{6}$ Es interesante el juego que despliega Kincaid en su obra con la noción de autobiografía. La novela que escribió antes que Mi hermano se titula Autobiografía de mi madre, y toma elementos de la vida de su madre en Dominica y Antigua. Por otra parte, el título Mi hermano parece ofrecer la historia no de la vida de la autora sino justamente la de su pariente. Sin 
ha reconocido en distintas entrevistas en relación con su producción literaria (Cudjoe; Bonetti; Cudjoe) ${ }^{7}$. Pero hay más. En este libro aparecen por primera vez los hermanos de Kincaid, quienes anteriormente solo habían recibido una breve (aunque dolorosa) mención en Lucy. El asfixiantes universo maternofilial de las relaciones familiares de las protagonistas de Kincaid admite por primera vez en Mi hermano la presencia protagónica de sus parientes masculinos más cercanos.

Mi hermano narra el período comprendido entre el momento en que Kincaid se entera de que su hermano menor, Devon, tiene SIDA y su muerte posterior. Desde el título y la apertura del texto el lector espera un protagonismo especial del hermano de la narradora. Sin embargo, como en una puesta en abismo, más que con una reconstrucción literaria de Devon, nos encontramos con una representación de la representación que la narradora tiene de su hermano. Muy pronto queda claro que Kincaid sabe muy poco de su hermano, a quien dejó de ver a los tres años y vuelve a ver recién veinte años después a raíz de su enfermedad. Y es a partir de su posición de testigo con poder (es la hermana exitosa, la migrante que logró dejar atrás la precariedad), que Kincaid trata de comprender quién es este hermano "en realidad", qué hay detrás de su actitud de macho conquistador y frívolo ocioso. Las tres primeras cuartas partes del libro están atravesadas por la relación ambivalente de Kincaid hacia su hermano, a quien a veces dice querer y otras odiar, por quien siente pena pero también irritación. Pero el protagonismo de Devon no se sostiene en forma consistente a lo largo del relato. La verdadera fuerza que impele a la narradora a indagar en la vida de su hermano parece provenir de la necesidad de comprenderse a sí misma. El hermano aparece así más como el espejo negativo de Kincaid (ella siente que él representa lo que ella hubiera llegado a ser sino hubiera escapado a Nueva York), que como sujeto que es posible conocer. El relato de la enfermedad, la mejoría temporal y la posterior muerte de Devon se realiza en permanente contrapunto con la narración de los recuerdos de infancia de Kincaid. Y en éstos, como también en el presente del reencuentro de la autora con su familia de Antigua, una de las figuras centrales es la madre. Finalmente es

embargo, el texto resulta mucho más claramente autobiográfico que el que lleva la palabra "autobiografía" en el título.

${ }^{7}$ Leigh Gilmore ha descrito la obra de Kincaid como una "autobiografía serial", que encarna un proyecto de autorrepresentación revisitado en cada uno de sus libros. 
ella lo que más tienen en común Devon, los otros dos hermanos y Kincaid. A partir del relato de los conflictos de sus hermanos con su madre (los que no son Devon solo aparecen mencionados en función de la relación difícil que tienen con su progenitora), Kincaid parece encontrar sustento "objetivo" para la terrible imagen de su madre que ha construido a lo largo de toda su obra. Si la madre es dominante, absorbente y opresiva con todos, entonces esa es una imagen "fidedigna", parece querer decirnos la narradora. "Imagen fidedigna" es una expresión que usa Kincaid para referirse al carácter polar de su madre: cuando sus hijos son vulnerables -están enfermos o son muy chicos para valerse por sí mismos- es capaz de los sacrificios más extremos por protegerlos; cuando, por el contrario, se fortalecen y son autónomos, las energías de la madre se vuelcan hacia su destrucción. Estas imágenes se ven reforzadas, como muchas otras a lo largo del libro, al ser puestas en relación con el mundo de las plantas: la madre arranca de raíz o quema los árboles que le ocasionan problemas. Además, el estilo reiterativo de la prosa de este libro - que lo acerca a la oralidad-garantiza que se establezcan con mucha claridad los atributos de cada uno de los personajes que transitan por sus páginas.

El relato se estructura así sobre el triángulo que conforman los tres personajes principales: Jamaica, Devon y la madre de ambos. Y si bien el tiempo principal de la narración corresponde al progreso de la enfermedad del hermano, los episodios más intensos se refieren a la rememoración del pasado de la autora en la isla. Dentro de su disfuncional familia, Kincaid es la que tiene buena memoria, la que es capaz de recordar los episodios que los demás -y sobre todo la madre- preferirían condenar al olvido. Es precisamente en relación con la memoria y las formas que asumen los recuerdos, que este libro de Kincaid resulta especialmente atractivo. El pasado inmediato al momento de la narración - un año después de la muerte del hermano, lo que le da la distancia necesaria para poder abordar el tema- está entrelazado con los recuerdos de infancia, y los procesos que llevan de un tiempo a otro son objeto de permanente reflexión. ¿Cómo se recuerda, por qué, cuáles son las asociaciones que llevan de una historia a otra, cuáles los caminos que sigue la memoria? A través de sus reflexiones, la narradora va dando cuenta de estas preguntas y ensayando posibles respuestas. Va mostrando, sobre todo, el carácter inevitablemente construido de los recuerdos, la imposibilidad de recuperar los sentimientos y sensaciones asociados a los hechos del pasado sin la mediación de todo lo vivido con posterioridad. Un hecho puede ser interpretado con rabia desde el futuro, pero no siempre se puede tener 
certeza de cuál fue el sentimiento con el que "de verdad" se lo experimentó (por ejemplo, al recordar su asistencia al funeral de un niño comenta: "todo aquello no me hizo sentir triste entonces, sólo ahora, cuando lo pienso, me siento triste", 161).

Los diques de contención que la narradora se esfuerza por construir para proteger su vida de Vermont de la contaminación de su pasado en Antigua, se ven permanentemente amenazados por los recuerdos del pasado que insisten en presentarse asociados a los eventos que rodean la enfermedad y muerte de Devon. Aunque la protagonista luche por no dejarse afectar y por conservar la calma ganada en su vida norteamericana, la situación límite que es la muerte la confronta con su condición de ser humano vulnerable, vinculado a otros, dependiente y frágil.

\section{LOS LAZOS QUE NOS CONSTITUYEN}

En un muy iluminador ensayo escrito a propósito de las reacciones del gobierno, la prensa y parte de la población norteamericana frente a los atentados del 11 de septiembre de 2001, Judith Butler reflexiona sobre el duelo, la pérdida y sus posibles implicancias para las personas y los colectivos que los sufren. Según esta autora, el hecho de que podamos ser víctimas de violencia -como el ataque a las torres gemelas- nos enfrenta a nuestra vulnerabilidad. Una de las respuestas posibles a esto es el ejercicio de una violencia en dirección opuesta, una respuesta agresiva y rabiosa, que no hace sino alimentar la espiral de violencia. ¿De qué manera, se pregunta Butler, podría aprovecharse esa conciencia de la vulnerabilidad para fundamentar otro tipo de política en vez de ser la justificación de nuevos ataques? Una política no violenta, sustentada en un verdadero trabajo de duelo, debiera desarrollarse sobre la base del reconocimiento de nuestro ser cuerpos vinculados con otros $\mathrm{y}$ del cuestionamiento a un ordenamiento global que permite y visibiliza ciertos duelos a la vez que condena otras muertes al total anonimato (¿Qué es lo que cuenta como humano, qué vidas cuentan como vidas, qué hace que una vida valga la pena?).

Las reflexiones de Butler en torno a las distintas dimensiones de la pérdida y el trabajo de duelo, permiten aproximarse a facetas de Mi hermano que ponen en crisis algunas interpretaciones que el libro parece sugerir en forma privilegiada. Si a nivel del contenido manifiesto este texto refuerza todas aquellas declaraciones y configuraciones literarias de Kincaid que relevan 
su construcción como autora singular y desvinculada de su comunidad de origen (y también de cualquier posible comunidad diaspórica caribeña en Estados Unidos), el análisis del trabajo de duelo realizado en la escritura misma muestra lo ilusoria que resulta esta pretensión de autonomía e individualidad extremas.

Recordando a Freud, Judith Butler releva lo difícil que resulta saber qué es lo que perdemos cuando alguien cercano deja de existir. La pérdida nos enfrenta a algo enigmático, a algo que no es posible determinar, que se escapa al conocimiento y la comprensión. Pero no es solo que no sabemos qué perdemos del otro, qué se fue con él, sino que además nos vemos enfrentados a la difuminación de algo de nosotros mismos. Esto debido a que la desaparición de alguien cercano pone en evidencia los lazos que nos ligan al otro, lazos que nos constituyen como sujetos: "Cuando perdemos algunos de los lazos que nos constituyen no sabemos quiénes somos ni qué hacer. Descubro que te he perdido 'a ti' solo para descubrir que yo también desaparezco" (48).

La vulnerabilidad del cuerpo expuesto a la violencia -o en el caso de Devon a una enfermedad que lo descompone y que lo confronta con un sistema de salud pública que no tiene contemplado asistir a enfermos que consideran desahuciados- conecta a los sujetos con las primeras relaciones que los constituyen. Estas se dan en el seno de la familia de origen, en el marco de vínculos que no se escogen y de los cuales depende totalmente la primera supervivencia. Butler nos recuerda que en tanto seres humanos y debido a nuestras necesidades corporales estamos entregados a una serie primaria de otros, que preceden a los procesos de individuación. La desesperación de Jamaica Kincaid en Mi hermano nace en gran medida de tener que reconocer, muy a pesar suyo, que ese proceso de individuación no consigue dejar totalmente atrás esa dependencia primera, esa no elegida red de personas de las que dependemos en nuestra infancia para poder sobrevivir. La enfermedad devuelve a Devon a la situación de dependencia con respecto a la madre y la familia. Toda la autonomía de la edad adulta se desvanece al tener que ser alimentado y limpiado por su progenitora. Es el retorno de la vulnerabilidad infantil, el desvanecimiento de la fantasía del poder adulto. Esto no solo afecta a Devon sino también a su hermana, quien se ve confrontada durante sus visitas a Antigua con este retorno a las experiencias familiares que más teme. 
La muerte de Devon agudiza el sentimiento de indefensión que gatilla la enfermedad. La pérdida del otro impulsa un trabajo de duelo que finalmente nos confronta a nosotros mismos, a nuestro ser cuerpos vinculados a otros. $Y$ además nos lleva a indagar cómo somos en relación con esa persona que se fue, quiénes somos luego de esa pérdida. El duelo nos arroja a una vorágine de preguntas, en su centro se encuentra el desconcierto y desconocimiento. Probablemente esto se tranquiliza y el duelo consigue ser elaborado "cuando se acepta que vamos a cambiar a causa de la pérdida sufrida, probablemente para siempre" (Butler 47).

Pero el cuerpo y el duelo tienen también una cara indudablemente pública. Así como el cuerpo nunca nos pertenece totalmente, tampoco el duelo puede ser concebido solo en términos de la experiencia privada, alejada de lo político. Para Butler el duelo ofrece una posibilidad de elaborar de otra manera el sentido de la comunidad política, que considere precisamente nuestra dependencia fundamental y las consecuencias éticas que ésta conlleva:

El duelo nos enseña la sujeción a la que nos somete nuestra relación con los otros en formas que no siempre podemos contar o explicar -formas que a menudo interrumpen el propio relato autoconsciente que tratamos de brindar, formas que desafían la versión de uno mismo como sujeto autónomo capaz de controlarlo todo. Podría intentar contar la historia de lo que estoy sintiendo, pero sería una historia en la que el "yo" es puesto en relación con el "Otro", una relación que no me reduce precisamente al silencio, pero que sin embargo satura mi discurso con signos de descomposición. Cuento una historia acerca de las relaciones que elijo solo para mostrar en algún lugar de la marcha el modo como esas mismas relaciones se apoderan de mí y desintegran mi unidad. Necesariamente, mi relato vacila (49).

"Vacilación" es un buen término para describir lo que experimenta la narradora de Mi hermano en relación con el relato de su vida y su reencuentro final con Devon. Su narrativa autoconsciente, contenida y sólida, va asumiendo progresivamente la incerteza y fragilidad como marcas constitutivas de la identidad de la protagonista. Ella no controla la fuerza del pasado que emerge en los recuerdos, no puede evitar amar a su hermano y su madre, y tampoco puede hacerlo sin ambivalencias. Pero finalmente el trabajo de duelo se va traduciendo en un reconocimiento profundo de la importancia de esos "otros" reprimidos en su historia de vida. Y al escribir el libro, al dar forma narrativa a ese proceso, también vincula este duelo privado a su dimensión pública. 
Como señala Butler, el espacio público también determina qué formas de duelo son aceptables y cuáles deben ser prohibidas. En el caso que ella analiza esto resulta evidente si se piensa en los miles de afganos, musulmanes, iraquíes y palestinos muertos a manos de soldados norteamericanos que no tienen espacio en los obituarios y cuyas vidas no son narradas por la prensa ni ningún medio de producción simbólica. Se trata de muertes reducidas al anonimato.

Devon también es condenado a una muerte anónima, con un funeral muy distinto al de la gente "respetable" de Antigua. Su muerte por SIDA lo hace sospechoso de haber sido homosexual y por lo tanto de no encajar dentro de los valores de su sociedad. Ya en el hospital al que lo llevan durante su enfermedad es trasladado a pabellones apartados del resto de los pacientes, más por la carga de culpa y responsabilidad propia que se le atribuye a los enfermos de SIDA que por criterios de salud. Esta segregación espacial continúa y se vuelve definitiva al momento del entierro: los que mueren de SIDA son enterrados en lugares apartados del cementerio local. Considero que en este contexto de segregación espacial de quienes enferman y mueren de SIDA, el libro de Kincaid puede leerse también como un acto de reparación y reposicionamiento de la figura de su hermano. Mi hermano sería entonces una forma de hacer público un duelo condenado al anonimato por los prejuicios de una sociedad. La muerte que se quiso ignorar y esconder es expuesta a un público mucho más amplio, frente al que se denuncia también los prejuicios y discriminación que tienen que enfrentar los enfermos de SIDA en Antigua.

\section{REFLEXIONES FINALES}

Señalábamos al principio de este artículo las importantes diferencias que existen entre la escritura de Jamaica Kincaid y la de otros autores diaspóricos en Estados Unidos. Uno de los aspectos que destacan en este sentido es el esfuerzo de la autora de construirse discursivamente como un sujeto desvinculado, que rechaza más que busca la conexión con los otros. Esto contrasta fuertemente con narrativas contemporáneas que enfatizan la importancia de rescatar y reconstituir, en situaciones de emigración, los lazos con las comunidades que permanecieron en el país de origen y con las que se constituyen en la diáspora. Frente a ideologías hegemónicas que construyen las imágenes del "sueño americano", el "self made man" y el éxito de la migración como un proceso de asimilación sin retorno a la cultura receptora, 
escritores como Junot Díaz, Michelle Cliff y Edwidge Danticat representan las dimensiones menos gloriosas (y más realistas) de la vida de los migrantes y rescatan las memorias y prácticas culturales de los países de origen.

Lo que se ha intentado mostrar en este artículo es como si bien Kincaid a nivel del discurso manifiesto pareciera encarnar y reproducir los discursos individualistas en torno a la migración y la individuación en general, una lectura más detenida muestra cómo también en su narrativa está presente la centralidad que tienen los lazos con los otros en la constitución de los sujetos. Muchas veces a contrapelo de lo que la narradora declara, con una fuerza que conmueve sus certezas y propósitos conscientes, en Mi hermano se configura una subjetividad protagónica cada vez menos capaz de negar la importancia de sus lazos con los otros de su primera infancia.

\section{BIBLIOGRAFÍA}

Bonetti, Kay. “An Interview with Jamaica Kincaid”. The Missouri Review. 15.2 (1992): 125-142.

Brophy, Sarah. “Angels in Antigua: The Diasporic of Melancholy in Jamaica Kincaid's My Brother”. PMLA, 117.2 (2002): 265-277.

Buckner, Brittnay. "Singular Beast: A Conversation with Jamaica Kincaid". Callaloo. 31.2 (2008): 461-469.

Butler, Judith. Vida Precaria. El poder del duelo y la violencia. Trad. Fermín Rodríguez. Buenos Aires: Editorial Paidós, 2006.

Balutansky, Kathleen.”On Gardening”. Callaloo 25.3 (2002): 190-800.

Caton, Louis. "Romantic Struggles: The Bildungsroman and Mother-Daughter Bonding in Jamaica Kincaids`s Annie John”. The Society for the Study of the Multi-Ethnic Literature of the United States (MELUS). 21.3 (1996): 125-142.

Clifford, James. Routes. Travel and Translation in the Late Twentieth Century. United States of America: Harvard University Press, 1997.

Covi, Giovanna. Jamaica Kincaid's Prismatic Subjects. Making Sense of Being in the World. London: Mango Publishing, 2003.

Cudjoe, Selwyn. "Jamaica Kincaid and the Modernist Project: An Interview”. Callaloo. 39 (1989): 396-411.

Gilmore, Leigh. "There Will Always Be a Mother. Jamaica Kincaid's Serial Autobiography”. The Limits of Autobiography. Trauma and Testimony. Ithaca and London: Cornell University Press, 2001. 96-119.

Kincaid, Jamaica. Mi hermano. 1997. Trad. Alejandro Pérez Viza. Santiago de Chile: LOM Ediciones, 2009. 
Kincaid, Jamaica. Lucy. New York: Farrar, Straus and Giroux, 1990.

Lejeune, Philippe. "Autobiografía e historia literaria". El pacto autobiográfico y otros estudios. Editor Ángel Loureiro. Madrid: Megazul-Endymion, 1994.

Lehmann, Sophia. "In Search of a Mother Tongue: Locating Home in Diaspora". The Society for the Study of the Multi-Ethnic Literature of the United States (MELUS). 23.4 (1998): 101-118.

Ramos, Julio. "Migratorias". Paradojas de la letra. Caracas: Universidad Simón Bolívar, 1996. 177-186.

Said, Edward. Reflections on Exile and Other Essays. Cambridge: Harvard University Press, 2003.

Soto-Crespo, Ramón. "Death and the Diaspora Writer: Hybridity and Mourning in the Work of Jamaica Kincaid”. Contemporary Literature. 43.2 (2002): 342-376.

Torres, Lourdes. "In the Contact Zone: Code-Switching Strategies by Latino/a Writers". The Society for the Study of the Multi-Ethnic Literature of the United States (MELUS). 32. (2007): 75-96.

Torres-Saillant, Silvio. El retorno de las yolas. Ensayos sobre diáspora, democracia y dominicanidad. Santo Domingo: Editora Manatí, 1999.

Vilches, Vanessa. De(s)madres o el rastro materno en las escrituras del yo (a propósito de Jacques Derrida, Jamaica Kincaid, Esmeralda Santiago y Carmen Boullosa). Santiago de Chile: Editorial Cuarto Propio, 2003. 